\title{
Selecting and Structuring Teaching Content Algorithm for Physical and Mathematical Disciplines, Aimed at Students' Project-Technical Competence Formation
}

\author{
Ilsiyar M. Zaripova ${ }^{1}$, Alfira M. Akhmedova ${ }^{2}$, Yuliya A. Chernova ${ }^{3}$, Renat N. Zaripov ${ }^{4}$, Tatyana A. Yuryeva ${ }^{5}$, \\ Natalya N. Dvoyeryadkina ${ }^{5} \&$ Natalya A. Chalkina ${ }^{5}$ \\ ${ }^{1}$ Almetyevsk State Oil Institute, Almetyevsk, Russia \\ ${ }^{2}$ Kazan (Volga region) Federal University, Kazan, Russia \\ ${ }^{3}$ Ulyanovsk State Agricultural Academy named after P. A. Stolypin, Ulyanovsk, Russia \\ ${ }^{4}$ Kazan National Research Technological University, Kazan, Russia \\ ${ }^{5}$ Amur State University, Blagoveschensk, Russia \\ Correspondence: Ilsiyar M. Zaripova, Almetyevsk State Oil Institute, Lenin Street, 2, Almetyevsk, Tatarstan, \\ 423450, Russia. E-mail: ilagni@mail.ru
}

Received: December 29, $2014 \quad$ Accepted: January 22, $2015 \quad$ Online Published: February 11, 2015

doi:10.5539/res.v7n4p6

URL: http://dx.doi.org/10.5539/res.v7n4p6

\begin{abstract}
The most important component of the professional competence of an engineer is the synthesis of project and technical competences-project-technical competence, suggesting a set of special knowledge, skills and proficiencies, personal qualities necessary for the effective specialists' performance of their professional duties, in particular, for the successful implementation of engineering projects requiring technical calculations running, capabilities to effectively operate in real life, to get oriented in production situations, to adapt to changing conditions, to work in different teams. In this connection, the problem of selecting and structuring teaching content of physical and mathematical disciplines, aimed at the formation of project-technical competence of technical university students, is becoming relevant. The paper presents an algorithm for selecting and structuring the physical and mathematical disciplines teaching content, aimed at the formation of students' project-technical competence, involving a sequence of analytical and preparatory, organizational-substantive, procedural-methodological, as well as correction-implemental stages. The article submissions are of practical value to Mathematics and Physics teachers for selecting and structuring the content of these disciplines.
\end{abstract}

Keywords: algorithm, selection and structuring, teaching content, project-technical competence, physical and mathematical disciplines, technical university

\section{Introduction}

As a methodological foundation of all natural sciences knowledge, mathematics and physics in a technical university serve as the basic theoretical disciplines. Due to the high degree of abstraction mathematics is a kind of foundation for all natural sciences and without it there cannot be any other sciences, which operate a quantitative data, so that it is a universal language to describe the real world and, therefore, in professional education without qualitatively mastering it a high quality training of a specialist is inconceivable (Frolov, 2008; Khairullina, 2007; Shaidullina, 2012; Merzon et al., 2015; Grigoryeva et al., 2015). The main goal in order of importance in studying mathematics and in mathematical education system is to master the actual subject itself, the application of mathematical knowledge for studying related disciplines of natural sciences cycle, as well as special disciplines (Miller, 2008; Vasilevskaya, 2000; Shershneva, 2011). No less important in studying mathematics appears to be its use by students in their future professional activities for studying engineering and technical production problems. Studying mathematics develops in students the flexibility, which is necessary for a future engineer, and intellectual rigor, it intellectually enriches them. The indisputable is the fact that at all stages of the science and technology development, of engineering, engineering solutions require constant calculations and computations, the proficiency to build mathematical models, skills to implement projects, which form an integral part of engineering. Courses in mathematics and physics in technical universities, as a rule, are 
delivered at the first and second years of study and are among the most difficult for students' understanding, as the main reasons of which the following circumstances can be included: a large amount of material on these disciplines has to be squeezed into the narrow framework of academic hours allotted to study them; most engineering students do not realize the need to study general education disciplines, which include mathematics and physics; mathematics operates with objects that do not exist in nature (Atakhanov, 1995; Borisov, 2006; Dorofeev \& Erganova, 2011; Levina et al., 2015).

As a result of superficial study of physical and mathematical sciences without regard to the general professional and special disciplines the students' knowledge and skills are poorly formed to enable them to properly navigate in the practical tasks, to use physical and mathematical knowledge to solve problems related to the future profession.

\section{Methodological Framework}

As methodological basis for the development of the selecting and structuring teaching content algorithm for physical and mathematical disciplines, aimed at the formation of technical university students' project-technical competence (PTC), the modular competency-based, integrative and project-targeted approaches are laid down.

Teaching physical and mathematical disciplines within the modular competency-based approach allows for: the integration of an invariant and variable parts of physico-mathematical training of students; personality-centered orientation of training by means of appropriate technologies; estimation of students according to level of competencies development with their classification according to quality indicators; activating the training and students' self-training processes; selection of promising students based on their potential capabilities and their further targeted training to meet the requirements of the modern labor market (Chugunova, 1991; Bakeeva, 2006).

The choice for the integrative approach is due to the fact that the formation of students' PTC in the study of physical and mathematical sciences will be effective when integrating students' study, research and practice; in implementation of the integrative capacity in intradisciplinary (between study units and disciplinary modules of training courses in mathematics and physics), interdisciplinary (between mathematics, physics and special disciplines) links; variative and invariant components of curriculum disciplines "Mathematics" and "Physics"; between academic and professional activity types of a future petroleum engineer; when integrating technologies for efficient formation of this competence (Mukhametzyanova \& Shaydullina, 2011; Masalimova et al., 2014).

As a part of the project-oriented approach a technical university students' project work in studying physical and mathematical sciences serves as an effective mechanism to achieve a specific practice-oriented objective, the effectiveness of which depends on the joint actions of the educational institutions subjects and the professional community in the process of future engineers' PTC formation. Accordingly, the design of the professionally-oriented physical and mathematical problems occurs through the integrated consideration of needs and interests of students' individualities, the intellectual potential of a technical university and requirements of the professional community of the petroleum industry in the region (Zaripov, 2004; Tambov, 2008).

On the basis of the highlighted approaches to the PTC formation of future petroleum engineers when studying physical and mathematical sciences, as well as taking into account the proposed points of view on selecting and structuring principles, being highlighted by the researchers, for mathematics and physics teaching content, we were guided by the following principles for selecting the content:

- Of systems, involving consideration of the PTC as a system that allows to carry out the content selection of the training material, aimed at complementarity and replenishment of both external and internal components: technical and project competences, mathematical and physical components (Romanova, 2010; Mukhina, 2003);

- Of integration, implying interdisciplinary and cross-thematic integrative links, integration of activities (study, research, project and production), traditional and innovative teaching technologies aimed at effective forming of PTC of future Petroleum Engineers (Kryazheva, 2009);

- Of professional orientation, implying that kind of a selection of these disciplines content in which the professionally oriented physical and mathematical problems represent a professional situation model, which can be studied with the help of physical and mathematical tools and promotes a future petroleum engineer's professional development (Kamaleeva \& Galimov, 2012; Hazova, 1985);

- Of modularity, implying structuring of educational material for informatively and organizationally complete training situations, projects that make up a single training content promoting gradual formation of students' PTC, their independent learning skills, training in a team, the development of reflexive abilities; 
- Of problematicity, implying the existence of problematic nature assignments and tasks in the content of teaching mathematics and physics, activating cognitive activity of students through that combination of content, forms, methods and means of instruction, which is based on the logic of students' search activities associated with the statement of problem situations, forming the basic thinking operations necessary in design processes of a future petroleum engineer;

- Of innovation, that is to systematically update the content and technologies for teaching physical and mathematical disciplines in accordance with the latest developments in the field of future Petroleum Engineers professional training (Vorontsova, 2009).

\section{Results and Discussions}

\subsection{The Steps of the Algorithm}

The algorithm for selecting and structuring the teaching content of physical and mathematical disciplines, aimed at the formation of students' project-technical competence, involves a sequence of analytical and preparatory, organizationally-substantive, procedural-methodological and correction-implemental steps.

\subsubsection{Analytical and Preparatory Step}

Analytical and preparatory step for selecting and structuring physical and mathematical disciplines teaching content, aimed at the formation of project and technical competence of a technical university students, involved all of the following actions:

- Requirements analysis of Federal State Educational Standards of Higher professional education, of employers to the level of formation of the professional competencies required of Petroleum Engineers for the effective implementation of future professional activity, PTC being a basic part of them;

- Identifying the levels of students' motivations to study physics and mathematics disciplines, self-assessment of the PTC development levels, knowledge of elementary mathematics, mechanical comprehension levels (Bennett tests), project skills;

- Detecting the factors contributing to and blocking the process of effective formation of students' PTC in the course of studying mathematics and physics.

\subsubsection{Organization-Substantive Step}

This step involves:

- Identification of common and specific topics and study units of physical and mathematical sciences disciplines, aimed at the PTC formation;

- The establishment of cross-thematic and interdisciplinary links of physical and mathematical disciplines with general professional and special disciplines;

- Development of competence-based study programs for physical and mathematical disciplines, aimed at students' PTC formation;

- Selection and structuring the content of physical and mathematical sciences disciplines, which is aimed at the students' PTC formation.

\subsubsection{Procedural-Methodological Step}

At procedural-methodological step of selecting and structuring teaching content of physical and mathematical disciplines, aimed at the formation of project-technical competence of technical university students the following steps were undertaken:

- Selection and development of training tasks and project assignments devoted to future Petroleum Engineers' PTC formation;

- Development of project-type assignments for students' independent work in research activities;

- Development of methods to use cognitive-motivational potential of physical and mathematical disciplines;

- Optimal combination of methods and technologies for the PTC formation when teaching physical and mathematical disciplines (use of the projects method, Internet technologies, annotation, the method of problem situations analysis, and others);

- Development and implementation in the educational process of students of a study guide "Physical and mathematical problems of interdisciplinary and professionally-oriented type";

- Development of diagnostic and training tests, control works, project tasks, the performing of which is directed 
to the formation of students' PTC when studying physical and mathematical disciplines.

At this stage, the students were solving the problems of Section I, developed by the author of the study guide "Physical and mathematical problems of interdisciplinary and professionally-oriented type" in each disciplinary module in classroom and extracurricular time with subsequent assessment of the accrued points (stimulation), monitoring of results and their discussion, and error correction; project tasks from Section II of this guide were performed; annotation for the topics was carried out, actualizing the relationship of mathematics and physics with related disciplines, disciplines of general professional cycle; reports prepared for participation in student research-to-practice conferences on topics that contribute to the formation of students' PTC, activating the application of mathematical and physical methods in solving technical and technological professional problems.

Depending on the ways to incorporate elements, that contribute to the formation of PTC, into the content of the educational material of physical and mathematical disciplines and on the nature of students' cognitive activities, there are three stages of the formation of this competence: in the first stage typical tasks are solved and creative mini-projects are developed; the formation of PTC is performed at the level of integration of interdisciplinary connections; the second stage is carried out by the cognitive movement from mathematical knowledge and skills to professional objects and methods of acting, developing the PTC; at the third stage of the studies students acquire practical experience in conducting project activities through introducing into the learning process the tasks for the development of the interdisciplinary nature projects which are a synthesis of teaching, research and project activities (Zaripova et al., 2014). At each stage the students' activities are aimed at obtaining the final product of designing activity: at junior courses - it is a nomination of their projects for participating in a student conference; at senior years - it is innovative entrepreneurship, willingness and readiness to bring the project activity result to its commercial realization.

In carrying out certain actions for the formation of students' PTC during the study of physics and mathematics, the results of their educational research and project activities were recorded in a "Map of personal achievements". Annotations, control and test papers with the analysis of results, proceedings of the research-to-practice conferences, and results of diagnostic and standardized tests were collected by students in their portfolios.

\subsubsection{Correction-Implemental Step}

At the correction-implemental step:

- Introduction and discussion of the developed algorithm for selecting and structuring teaching content of physico-mathematical disciplines were held, aimed at the formation of project-technical competence of a technical university students at faculty meetings of State Budgetary Educational Institution "Almetyevsk State Petroleum Institute", as well as at research-to-practice conferences at various levels;

- Personality, cognitive, operational and reflexive criteria and their indicators were developed to diagnose levels of students' PTC formation during the study of physico-mathematical disciplines;

- Best practices for the formation of students' PTC were developed during the study of other disciplines.

\subsection{The Progress and Description of the Experiment}

To assess the level of formation of the students' project-technical competence, it was decided to adopt a three-level gradation: low, medium and high. The threshold (low) level of the competence development involves a student's ability to solve only individual problems in an activity being formed and a limited ability to orient in an environment, which may lead to incorrect use of the available methods that do not correspond to the real conditions of the problem. The increased (medium) level of the competence development is characterized by the ability to solve certain problem groups of the activity being formed with understanding the conditions and limits of the methods applicability in solving them. The high level implies the ability to solve any problems identified within the activity being formed using various methods and taking full account of the existing conditions of the problem.

Identification of the baseline in the project-technical competence was conducted at the beginning of the academic year prior to the study of advanced maths. 
Table 1. Diagnostic results of $1^{\text {st }}$ and $2^{\text {nd }}$-year students' competences formation levels at the ascertaining stage, $\%$

\begin{tabular}{lllllllll}
\hline & $\begin{array}{l}\text { personal } \\
\text { contrl }\end{array}$ & experm & $\begin{array}{l}\text { cognitive } \\
\text { contrl }\end{array}$ & experm & $\begin{array}{l}\text { activity } \\
\text { contrl }\end{array}$ & experm & $\begin{array}{l}\text { ceflexive } \\
\text { contrl }\end{array}$ & experm \\
\hline low & 13.2 & 11.1 & 21.1 & 25.0 & 13.2 & 11.1 & 26.3 & 25.0 \\
medium & 73.7 & 80.6 & 68.4 & 61.1 & 76.3 & 75.0 & 60.5 & 58.3 \\
high & 13.2 & 8.3 & 10.5 & 13.9 & 10.5 & 13.9 & 13.2 & 16.7 \\
$2^{\text {nd }}$ year & & & & & & & & \\
low & 2.6 & 5.6 & 7.9 & 5.6 & 13.2 & 11.1 & 26.3 & 25.0 \\
medium & 73.7 & 80.5 & 78.9 & 75.0 & 76.3 & 75.0 & 60.5 & 58.3 \\
high & 23.7 & 13.9 & 13.2 & 19.4 & 10.5 & 13.9 & 13.2 & 11.1 \\
\hline
\end{tabular}

The reliability of differences in the levels of the project-technical competence formation was checked by $\chi^{2}$ criterion, which showed no significant differences in the diagnosed groups $\left(\chi^{2} \mathrm{calc}=2.8, \chi^{2} \mathrm{calc}=5.9 ; \chi^{2} \mathrm{calc}\right.$ $<\chi^{2}$ crit). This let us take the $1^{\text {st }}$ flow groups as control ones, the $2^{\text {nd }}$ flow groups as experimental.

At the forming stage of the experiment (2009-2012 academic years) the developed research-to-learning-and-teaching support was being introduced in the educational process of the higher school for the formation content of the students' project-technical competence, as well as the algorithm for forming students' project-technical competence during the study of mathematics and physics, there was carried out continuous monitoring of the students' project-technical competences development levels, according to which these disciplines teaching content was being updated.

At the final stage of the experiment (2012-2014 academic year) the dynamics of the students' project-technical competence formation level was being identified — of future petroleum workers, before and after the formative stage of the experiment, of the changes in the teachers' attitudes to the need for forming the project-technical competence, recommendations for teachers of higher and secondary vocational schools were being developed for forming and developing students' project-technical competence when studying the disciplines of mathematical and natural sciences cycle.

Table 2. Diagnostic results of $1^{\text {st }}$ and $2^{\text {nd }}$-year students' competences formation levels at the final stage, $\%$

\begin{tabular}{lllllllll}
\hline & $\begin{array}{l}\text { personal } \\
\text { contrl }\end{array}$ & experm & $\begin{array}{l}\text { cognitive } \\
\text { contrl }\end{array}$ & experm & $\begin{array}{l}\text { activity } \\
\text { contrl }\end{array}$ & experm & $\begin{array}{l}\text { reflexive } \\
\text { contrl }\end{array}$ & experm \\
\hline low & 10.2 & 11.2 & 10.5 & 3.6 & 11.2 & 4.5 & 21.3 & 10.6 \\
medium & 75.3 & 63.2 & 78 & 70 & 79.3 & 67.7 & 53.1 & 50.7 \\
high & 14.5 & 25.6 & 11.5 & 26.4 & 9.5 & 27.8 & 25.6 & 38.7 \\
$2^{\text {nd }}$ year & & & & & & & & \\
low & 3.1 & 2.1 & 2.1 & 3.6 & 2.3 & 2.6 & 2.3 & 2.6 \\
medium & 71.5 & 65.4 & 69 & 61.9 & 84.9 & 58.5 & 84.9 & 58.5 \\
high & 25.4 & 32.5 & 28.9 & 34.5 & 12.8 & 38.9 & 12.8 & 38.9 \\
\hline
\end{tabular}

Analysis of the results showed that in the experimental groups more students had passed on to the medium level of the project-technical competence development, while in the control groups there had not been significant changes. We checked the reliability of differences by $\chi^{2}$ criterion.

\section{Conclusion}

The essence of a technical university students' project-technical competence formation in the course of studying mathematics and natural sciences disciplines lies in the synthesis of project and technical competencies, involving the acquisition of special knowledge, proficiency, skills and personal qualities necessary for specialists' effective professional duties performance, associated with implementing engineering projects with the 
performance of complex technical calculations that require the capabilities to effectively behave in a professional activity, for orientation in nonconventional production situations, adapting to changing production-necessary conditions for carrying out engineering design works in various labor groups.

Selecting and structuring the teaching physics and mathematics content, aimed at the formation of project-technical competence of future engineers, are carried out taking into account its focus on the end product of design activity: at junior level courses - it is a nomination of a student's project to participate in a student conference; at senior courses - it is innovative entrepreneurship, willingness and readiness to bring the results of the activity to commercial realization. The algorithm involves the totality and sequence of analytical and preparatory, organizationally-substantive, procedural-methodological, and correction-implemental steps.

\section{References}

Atakhanov, R. A. (1995). The ratio of the general laws of thinking and mathematical thinking. Questions of psychology, 5, 41-50.

Bakeeva, L. V. (2006). Trends in the development of mathematics education in technical universities in the Republic of Tatarstan (p. 23). Kazan.

Borisov, L. A. (2006). Development of technical skills of students on the basis of information technology education (p. 23). Kazan.

Chugunova, E. L. (1991). Complex social, psychological methods of studying personality Engineer (p. 181). Leningrad.

Dorofeev, A. V., \& Erganova, N. E. (2011). Multidimensional mathematical training as a factor in the formation of the future teacher metekompetentsy. Kazan pedagogical journal: Kazan, 1, 5-12.

Frolov, N. A. (2008). Ways to improve the training of specialists with innovative educational technologies. Higher education today, 6, 29-31.

Grigoryeva, E. V., Leyfa, I. I., Yatsevich, L. P., Demyanenko, M. A., Makovey, N. V., Pavlushkina, T. V., \& Masalimova, A. R. (2015). Designing a Structure of the Modular Competence-Based Curriculum and Technologies for Its Implementation into Higher Vocational Institutions. Review of European Studies, 7(1), 123-129.

Hazova, C. (1985). Development of the need to work in students professional technical schools (p. 144). Moscow: Higher School.

Kamaleeva, A. R., \& Galimov, A. N. (2012). Technology development is naturally variable programs, math and general professional disciplines to meet the requirements of the third generation standards and training areas (p. 32). Kazan: Kazan Univ.

Khairullina, E. R. (2007). Principles pedagogical concept design, creative activity of students. Higher education today, 9, 66-68.

Kryazheva, E. V. (2009). Development of technical thinking of future specialists on the basis of interdisciplinary integration (p. 179). Yaroslavl.

Levina, E. Y., Saglam, F. A., Skorobogatova, A. I., Shaikhlislamov, A. Kh., Sagitova, V. R., \& Fayzullina, A. R. (2015). Quality Control Optimization of University Students Training. Asian Social Science, 11(2), 296-300.

Masalimova, A. R., Schepkina, N. K., Leifa, A. V., Burdukovskaya, E. A., \& Shaidullina, A. R. (2014). Mentoring perfection in modern enterprises conditions: Practical recommendations. American Journal of Applied Sciences, 11, 1152-1156. http://dx.doi.org/10.3844/ajassp.2014.1152.1156

Merzon, E. E., Fayzullina, A. R., Ibatullin, R. R., Krylov, D. A., Schepkina, N. K., \& Pavlushkina, T. V. (2015). Organizational and pedagogical conditions of academic mobility development of students at school of higher professional education. Review of European Studies, 7(1), 46-51.

Miller, A. A. (2008). Pedagogical model of the formation of the technical competence of cadets of the higher military educational institution (p. 23). Novokuznetsk.

Mukhametzyanova, G. V., \& Shaydullina, A. R. (2011). Integration processes in the regional system of vocational education (p. 232). Kazan: Idel Press.

Mukhina, M. V. (2003). Development of technical thinking in the future teacher of technology and business system means of cognitive tasks (p. 24). Nizhny Novgorod.

Romanova, A. M. (2010). Formation of professional, creative orientation of students of a technical college (p. 23). 
Moscow.

Shaidullina, A. R. (2012). Regional Experience of Integration in System Vocational School-High School-Manufacture. Memoirs of Almetyevsk State Oil Institute, 2, 306-312.

Shershneva, V. A. (2011). Formation of mathematical competence of students of engineering high school on the basis of multiparadigmatic approach (p. 210). Krasnoyarsk.

Tambov, G. (2008). Formation of the technical competence of the cadets of the military, engineering schools (p. 20). Chelyabinsk.

Vasilevskaya, E. A. (2000). Professional orientation of mathematics teaching engineering students (p. 26). Moscow.

Vorontsova, O. R. (2009). Formation of informative independence of students of a technical college for teaching mathematics using Web, technology. Yaroslavl Pedagogical Gazette, 3, 107-111.

Zaripov, Z. F. (2004). Invariant approach to the development of mathematical culture of students, future engineers (p. 23). Kazan.

Zaripova, I. M., Shaidullina, A. R., Upshinskaya, A. Y., Sayfutdinova, G. B., \& Drovnikov, A. S. (2014). Modeling of Petroleum Engineers Design-Technological Competence Forming in Physical-Mathematical Disciplines Studying Process. American Journal of Environmental Sciences, 1049-1053.

\section{Copyrights}

Copyright for this article is retained by the author(s), with first publication rights granted to the journal.

This is an open-access article distributed under the terms and conditions of the Creative Commons Attribution license (http://creativecommons.org/licenses/by/3.0/). 